\title{
A strategy for acquiring customer requirement patterns using laddering technique and ART2 neural network
}

\author{
Chun-Hsien Chen*, Li Pheng Khoo, Wei Yan \\ School of Mechanical and Production Engineering, Nanyang Technological University, North Spine (N3) Level 2, 50 Nanyang Avenue, \\ Singapore 639798 Singapore
}

\begin{abstract}
With the increasing interest and emphasis on customer demands in new product development, customer requirements elicitation (CRE) and evaluation have secured a crucial position in the early stage of product conceptualization. As such, it is highly desired to have a systematic strategy for soliciting customer requirements effectively, and subsequently, analyzing customer orientations quantitatively. For this purpose, a customer-oriented approach has accordingly been proposed and investigated in this study. It concerns both breadth and depth perspectives of customer requirements acquisition as well as customer and marketing analysis. This prototype system comprises two interrelated components, namely, the CRE and the customer/marketing analysis (CMA) modules. The process starts from the voice of customers and ends with the identified opportunities from marketing analysis. In the prototype system, the laddering technique has been employed to enable CRE via the so-called customer attributes hierarchy (CAM). In addition, the adaptive resonance theory, particularly ART2, neural network has been applied as a toolkit for further customer and marketing analysis. A case study on wood golf club design is used to demonstrate and validate this approach.

(C) 2003 Elsevier Science Ltd. All rights reserved.
\end{abstract}

Keywords: Customer requirement patterns; Marketing analysis; Laddering technique; Adaptive resonance theory neural network; Customer segmentation; Competition analysis and customer trends analysis

\section{Introduction}

Customer requirements management evolves from the notion of 'Customer is always right' [1]. Over the years, this has grown and developed into a prominent philosophy in marketing and engineering, where customer is the key to the success of an organization and its new product development (NPD). Accordingly, many organizations have acted upon it to bring into existence products and services to satisfy customer requirements [2]. Marketing analysis has been treated as one of the core phases during product concept development in much research work. A variety of approaches have been proposed for dealing with

- conventional corporate marketing as a strategic business policy, such as service marketing, low-cost marketing, industrial market segmentation, sales forecasting, and order-winning criteria [3-7]; and

- current corporate niche via the Internet-based strategies, such as computer-assisted marketing, post-Internet

\footnotetext{
* Corresponding author. Tel.: + 65-6790-4888; fax: + 65-6791-1859.

E-mail address: mchchen@ntu.edu.sg (C.-H. Chen).
}

marketing, and high-technology innovation marketing [8-10].

Apart from the aforementioned research aspects, a number of customer-related marketing approaches have been developed due to the increasing important role of customers in today's business environment. These approaches include customer satisfaction, customer marketing, customer-based method, customer-driven evolutionary system, customer loyalty, and customer relationship management [11-16]. Amongst them, Curry [12] first postulated the so-called customer marketing for identifying, acquiring, keeping and developing customers. In this approach, the strategy of customer pyramid, which includes the volume of customers, prospects and suspects, was applied to define the goals, orientation, database and behavior of customers as well as the mix of methods and media. Recently, the CRM has become a focus in today's marketing research [16]. A number of theories have been proposed to study the potential values of relationship marketing in customer markets. These theories include neoclassical microeconomic theory, transaction cost theory, relational contracting theory, social exchange theory, 
equality theory, political economic theory, and resource dependency theory [17-23]. Nevertheless, the following perspectives need to be further investigated before these theories can be applied for product concept development [24]: (1) the role of theories underlying relationship marketing other than customer behavior theory has hardly been examined in exploring the nature and development of customer relationships; and (2) no critical assessment has been made for the role that relational theories can play in determining the relative 'relationship-friendliness' of a particular customer situation, which reduces the risk of wasting critical resources.

Although a clear understanding of customers and markets through marketing research is of paramount importance, there are other factors to consider as well for managing customer requirements in NPD [25]. The socalled 'micro' and 'macro' perspectives proposed by Kotler [26] can be used to explain the different ways with which customer requirements are evaluated. From the micro perspective, the functional correlation between customer requirements and design specifications, which form a product-customer interface, is largely influenced by engineering considerations. On the other hand, the macro perspective requires broader socio-cultural factors, such as multicultural factors, competitions and customer trends, to be taken into consideration. Such a perspective is based on the assumption that customer requirements elicited from one customer group may have considerable conflict with another. The conflict may result from the fact that different nations possess different political systems as well as social and cultural environment. The variations must be considered during the early stage of product design [27]. The ultimate objective of adopting a macro perspective in NPD is to achieve better customer satisfaction in the global marketplace.

In the fast changing world, organizations need to interact and react to changes rapidly. The theory of the survival of the fittest [28] can be applied to today's fast changing business environment. To adapt to the environment or react quickly to customer requirements, Lancaster and Massingham [25] highlighted the essential stages in an environmental scanning and appraisal system. These stages include the identification upon key environmental factors, the forecasting of the trends in key environmental factors, the assessment of potential impacts of environmental trends and changes, and the adaptation to the environment for product development. With this approach, Lancaster and Massingham [29] examined some of such environments as the competitive environment, the socio-cultural environment, and the technological environment.

However, a systematic marketing analysis on customer issues for facilitating early product conceptualization is still lacking. It appears that the following aspects should be taken into consideration to ensure an organization's survival and prosperity: (1) Customer requirements acquisition and representation. Genuine customer voices need to be effectively elicited and represented [30]; (2) Multicultural customer factors analysis. Organizations ought to better recognize individual customer needs, to directly interact with customers, to quickly respond to their preference, and to effectively differentiate product or service offerings from them [31]; (3) Customer groups segmentation. Customer segmentation should be emphasized under the intensifying competition pressures [32]; and (4) Quantitative customer evaluation. Individual customers should be put in a more direct contact with manufacturers or organizations via a channel using information technologies [16]. As such, it is highly desirable to realize a systematic approach to tackle the above-mentioned for the analysis of customer requirements quantitatively as a preliminary investigation for the subsequent product concept formation. The gaps between existing marketing analysis methods and the proposed customer-oriented approach should be addressed. In this respect, customers are the core element to be considered, and can be regarded as the starting point, i.e. the leading driver or source in marketing analysis or prediction, in the early stage of a product conceptualizing process.

Based on this notion, a prototype system that concerns with broader customer requirements acquisition as well as deeper CMA is proposed and described in this paper. The prototype system, which emphasizes the customers' perception of a specific product and the conflict of customer requirements derived from multicultural customer groups, comprises two major components, namely a CRE module and a CMA module. It attempts to establish a systematic customer-product interface that starts from the voice of customers and ends with the identified opportunities from marketing analysis. In other words, the prototype system focuses on how to maximize customer involvement in relation to product concept development. Section 2 describes the CRE module and provides the details of the laddering technique and its implementation for establishing a CAH. Section 3 depicts the CMA module and presents an adaptive resonance theory (ART2 in particular) neural network for further customer requirements evaluation and marketing analysis. In Section 4, a case study on wood golf club design is used to validate the prototype system and a detailed discussion on the results is provided. The last section, Section 5, summarizes the main conclusions reached in this work.

\section{The customer requirements elicitation (CRE) module}

\subsection{Related work}

It was suggested by Louder and Bitta [33] that a number of complex customer behaviors such as perceptions, motivations, attitudes and personality can be grouped under psychological factors to make rational decisions. These factors influence the way in which customers select, organize and interpret a company and its products. Such 
a process can be realized by grouping information into categories or combining it under specific images. For this purpose, laddering technique [34] presents a logical alternative. The technique assumes that customers know their needs and are able to group them into different categories [30]. It provides a novel way for transforming psychological factors into useful inputs for design applications.

Laddering is a structured questioning methodology derived from Kelly's repertory grid technique [35]. It was initially developed by Hinkle [36] for classifying the relations between the constructs and organizing them into hierarchical relations. Similar to other 'contrived' knowledge elicitation techniques such as repertory grid and sorting techniques, it was originated in the domain of psychology [37]. It has been applied with increasing frequency in the field of knowledge acquisition and used as a 'technique' in its original form in predefined interviews as well as in the form of 'tools' for a computerized system $[38,39]$. As such, it appears that laddering has been developed to associate with more 'non-contrived' or 'natural' techniques such as interviewing and self-report [40].

Although requirements elicitation somehow differentiates from knowledge elicitation that has been widely applied for expert systems, Shaw and Gaines [41] suggested that (1) methodologies or tools involving knowledge elicitation have some applicability in requirements elicitation for product development; and (2) closer collaboration between knowledge engineering and requirements engineering will be mutually beneficial. As such, Maiden and Rugg [42] proposed a framework called acquisition of requirements (ACRE) to assist practitioners in understanding the strengths and weaknesses of each of the methods for requirements elicitation. It has been established that compared with other existing requirements acquisition methodologies, such as observation, interview, protocol and ethnographic, sorting and laddering technique have the following advantages: (1) broad coverage of domain for requirements elicitation; (2) time-saving for both preparation and acquisition sessions; (3) less expert guidance during requirements elicitation; (4) suitable for dataconcerned, non-tacit and recognized requirements elicitation; (5) friendly to elicitor and respondents; and (6) standardized format that is fit for computerized automation. Based on these understandings, in previous work, laddering as well as sorting techniques have been investigated in the elicitation of customer requirements for product concept development [43-45].

\subsection{The laddering technique}

Laddering resembles a form of structured interview in which the interviewer uses a limited set of standard questions to elicit respondent (customer) requirements. It is based on the assumption that respondent requirements are organized as a polyhierarchy, that is, a multidimensional or multifaceted set of hierarchies. Laddering provides a structure for the elicitation of information using a 'facet', which is a convenience way to describe individual hierarchy and decomposition requirements. Based on the work by Rugg and McGeorge [34], an improved procedure of the laddering technique for CRE during product concept development is summarized as follows [44]. Table 1 shows the definitions of terminology used in laddering technique.

Step 1 selecting/faceting a seed item. An interviewer or domain expert first selects a seed item, which is a point within the domain in question, from any level within the hierarchy. For example, any imposed construct, superordinate construct or verbatim construct can be selected as a seed item. It is recommended that several sessions be conducted, each time for a facet or 'dimension', e.g. a specific imposed construct.

Step 2: preparing/phrasing the probes. The interviewer uses probing questions to move around the structure embedding the seed item. Some of the frequently used probes or phrasings include 'is-a', 'has-goal' and 'part-of'.

Step 3: directing/leveling the semantics. Different prompt is recommended to alter the direction once laddering is not possible to go any further in a particular direction, so-called 'bottoming out' or 'topping out'.

Step 4: decomposing/classing the explanations. Explanations are then decomposed recursively until terms such as classes, attributes and entities bottom out, the depth of which can be treated as an indication of requirement complexity, also known as elucidatory depth.

Step 5: recording/coding the sessions. Several coding methods are available for laddering, including paper record, graphic representation and pseudo-production rule. Appropriate labeling that displays the names of classes and attributes is advisable.

Step 6: analyzing/post-processing the results. This enables the elicitors to gain insights into the results of

Table 1

Definitions of terminology used in laddering technique

\begin{tabular}{lll}
\hline Terminology & Definition & Example \\
\hline Verbatim construct & An attribute used by an individual to describe something & Light weight \\
Superordinate construct & The attribute grouped from the criteria in a higher abstraction level & Use new material to reduce weight \\
Imposed construct & The high-level attribute abstracted from the superordinate construct & Usability \\
\hline
\end{tabular}



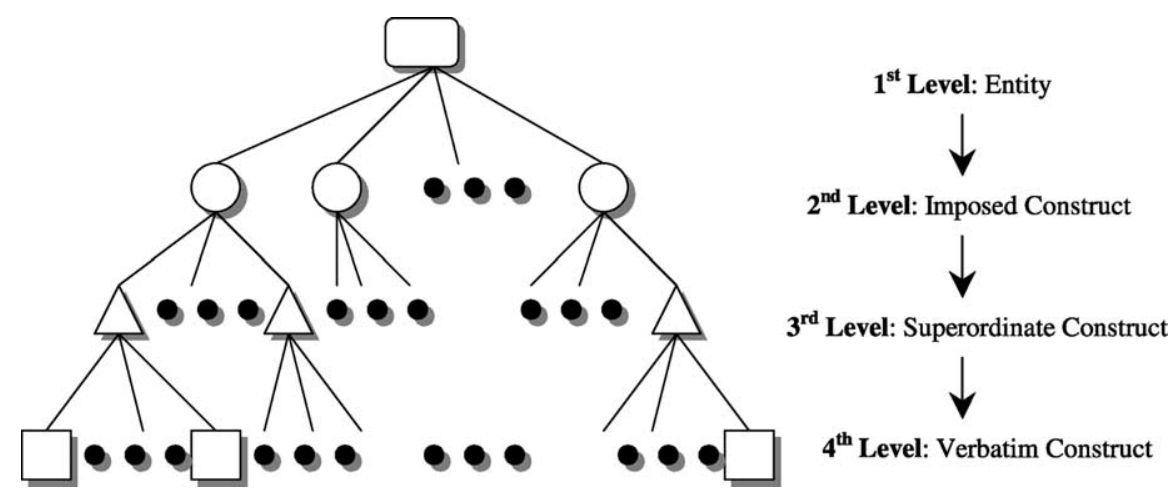

Fig. 1. Illustration of $\mathrm{CAH}$.

laddering. Quantitative analysis can be employed to postprocess the results obtained.

In this study, laddering is used as a CRE technique in order to derive the $\mathrm{CAH}$ (Fig. 1), which is regarded as a customer-explored architecture and used in the front-end of the prototype system. CAH is a generic taxonomy, which is set up by a domain expert according to the significance of the results of performing laddering on the voice of customers. The process of laddering can be treated as a set of psychological semantics of customers' perception about a specific product, which is an interaction of customer involvement. It comprises a four-level architecture topping down from the highest level to the lowest level for laddering for customer attributes. In this taxonomy, verbatim construct stands for voice of customer, and the imposed constructs will then be graded to generate the importance ratings (the CMA Module in Section 3).

\section{The customer/marketing analysis (CMA) module}

\subsection{Related work}

It was assumed that customer requirements elicited from one customer group might have considerable conflict with another. The conflict may derive from some multicultural factors, e.g. the demographic customer characteristics as age or gender. Hence, the variation must be considered during the early stage of product development [27]. As such, it is imperative to detect customer requirements from different customer groups, and thereafter, analyze these requirements using a single technique to bridge customer's demands with a company's products. It consists of four perspectives for this purpose as follows.

Perspective 1: multicultural customer groups analysis. Schiffman and Kanuk [46] postulated that customer groups could be classified according to culture difference. The multicultural factors can be dynamic and include subculture, social class, and group and family [47].

Perspective 2: major customer groups analysis. It was pointed out by Stanton et al. [48] that the overall customer group or market is composed of significantly different groups or sub-groups, that is, a heterogeneous mass, but often sufficiently similar as customer groups (or markets) in terms of specific products. As outlined by Lancaster and Massingham [29], the advent in NPD technologies makes product differentiation possible with little impact on the economics of NPD.

Perspective 3: competition/competitors analysis. The process of identifying the 'strategic fit' or 'market fit' is dependent on external (environmental) factors and an important facet of it is competition analysis. As observed by John et al. [49], the key scenarios/issues include catch-up position, where competitors provide better products or services than the company, current strength, where the company provides better products or services than its competitors and an opportunity, where no company is judged to be superior.

Perspective 4: customer trends analysis. Stanton et al. [48] suggested that forecasting for customers and markets must be the starting point of the NPD as this is the act of giving advance warning for beneficial action to be taken. Furthermore, Clifton et al. [50] found that the problems to be overcome in the forecasting scenario rest with customer trends analysis instead of cost accounts. Based on this understanding, the real nature of the product can be predicted from customer's perception of it.

After the laddering process for CRE, imposed constructs are accordingly obtained due to the multilevel architecture of laddering process. Usually, the imposed constructs contain ambiguity, and subjective and qualitative inherence with overlaps and conflicts. However, laddering alone is insufficient in handling concepts that are fuzzy and have no clear-cut boundary between sets of objects [34]. In this work, a neural network approach to group the information obtained from laddering into patterns regarding different customers is proposed and implemented as part of a prototype system (Fig. 2).

It has been proven that neural network is one of the most effective artificial intelligence (AI) techniques for multidisciplinary applications, of which business-based or marketing-related strategy is becoming a popular domain 


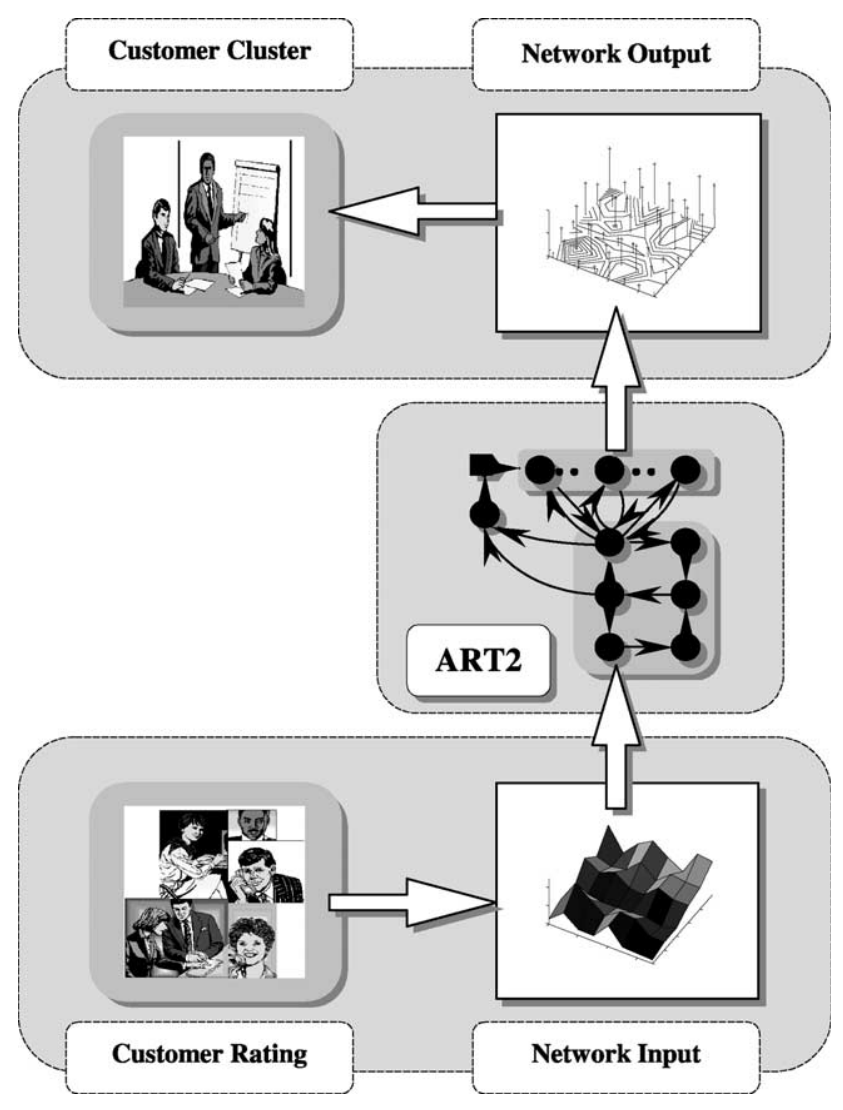

Fig. 2. Framework of a prototype system.

[51]. In a previous work, the feed-forward neural networks, such as backpropagation (BP) network [52] and radial basis function (RBF) network $[43,44]$, have frequently been employed in tackling marketing segmentation or forecasting. On the other hand, the self-organized neural network such as Kohonen's feature map (KFM) algorithm [53,54] has increasingly been accepted as a cluster analysis tool-kit in this area. In this study, the ART2 neural network algorithm is adopted for the following reasons.

1. Similar to other neural network strategies, it can plastically adapt to such complex (often uncertain or inconsistent) and correlated (non-linear and not isolated) situations in market analysis rather than those linear functions such as K-means clustering model [55];

2. To cope with the scarcity, incompleteness and imprecision of design information elicited in the early stage of product conceptualization, a self-organized algorithm instead of a supervised neural network appears to be a good approach for it does not require large samples and pre-determined targets [56]. Such an approach is suitable for preliminary clustering, rather than detailed classification, in marketing analysis; and

3. Compared with aforementioned KFM algorithm, it can deal with pattern recognition more flexibly and independently due to automatic detection of output patterns [57].

\subsection{Algorithm of the ART2 neural network}

The customer importance ratings of imposed constructs (an $n \times k$ matrix with $n$-dimensional ratings and $k$-dimensional respondents) are used as the inputs to the ART2 network for automated customer clustering of output patterns. The ART2 network is an unsupervised neural network with an ART architecture for performing both continuous-valued vectors and binary-valued vectors. A typical ART2 architecture was first proposed by Carpenter and Grossberg [58] as shown in Fig. 3 (only one unit of each type is shown here). In the attentional sub-system, an input pattern $\mathbf{s}$ is first presented to the $F_{1}$ layer, which consists of six kinds of unit, viz. the $W, X, U, V, P$ and $Q$ cells. It then undergoes a process of activation, including normalization, noise suppression and updating. This results in an output pattern $\mathbf{p}$ from the $F_{1}$ layer. Responding to this output pattern, an activation is produced across $F_{2}$ layer through bottom-up weights $b_{i j}$. As the $F_{2}$ layer is a competitive layer with a winner-take-all mode, only one stored pattern is a winner. It also represents the best matching pattern with the input pattern from the $F_{1}$ layer. Furthermore, the pattern of activation on the $F_{2}$ layer brings about an output pattern that is sent back to the $F_{1}$ layer via top-down weights $t_{j i}$.

For the orienting sub-system, it contains a reset mechanism $R$ and a vigilance parameter $\rho$ to check for the similarity between the output pattern from the $F_{2}$ layer and the original input pattern from the $F_{1}$ layer. If both patterns are concordant, the neural network enters a resonant state where the adaptation of the stored pattern is conducted. Otherwise, the neural network will assign an uncommitted (inhibitory) node on the $F_{2}$ layer for this input pattern, and thereafter, learn and transform it into a new stored pattern. The training algorithm can be described as the following steps.

Step 1. Initialize parameters of $a, b, c, d, e, \theta, \alpha$ and $\rho$, where $a, b$ are the fixed weights in the $F_{1}$ layer, $c$ is the fixed weights used in testing for reset, $d$ is the activation of winning $F_{2}$ unit (also satisfies $c d /(1-d) \leq 1$ ), $e$ is a small parameter to prevent division by zero when the norm of a vector is zero, $\theta$ is the noise suppression parameter (generally $\theta \cong 1 / n^{1 / 2}$ ), $\alpha$ is the learning rate, and $\rho$ is the vigilance parameter (usually $0.7 \leq \rho<1$ ). Then, randomly select an input vector $\mathbf{s}$ and proceed to Step 2 .

Step 2. Update $F_{1}$ unit activation using Eqs. (1)-(7). Initially, let $u_{i}=0, p_{i}=0$ and $q_{i}=0$ (where the number of input patterns $i=1,2, \ldots, n)$, thereafter, update $F_{1}$ unit activation again.

$$
\begin{aligned}
u_{i} & =\frac{v_{i}}{e+\left\|_{v}\right\|} \\
w_{i} & =s_{i}+a u_{i} \\
p_{i} & =u_{i} \\
x_{i} & =\frac{w_{i}}{e+\left\|_{w}\right\|}
\end{aligned}
$$




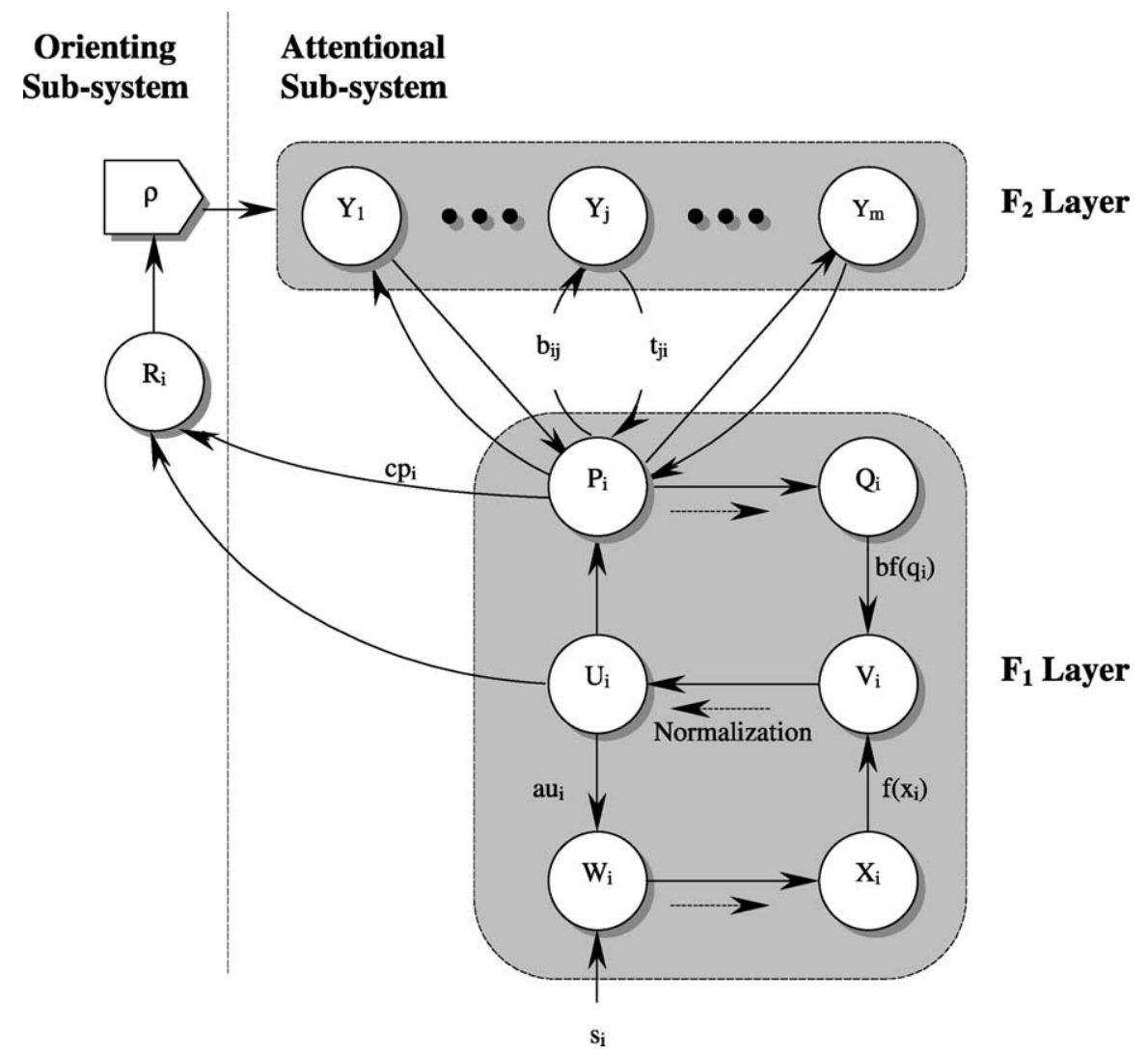

Fig. 3. Typical architecture of ART2 neural network.

$q_{i}=\frac{p_{i}}{e+\|p\|}$

$v_{i}=f\left(x_{i}\right)+b f\left(q_{i}\right)$

where the activation function is

$f(x)= \begin{cases}x & \text { if } x \geq \theta \\ 0 & \text { if } x<\theta\end{cases}$

Step 3. Compute signals to $F_{2}$ units, and find $Y_{J}$ with the largest signal (assuming that $y_{J} \geq y_{j}$, for $j=1,2, \ldots, m$, where $m$ is the number of output patterns).

$y_{j}=\sum_{i} b_{i j} p_{i}$

Step 4. Check for reset by updating $u_{i}$ according to Eq. (1), along with using Eqs. (9) and (10).

$p_{i}=u_{i}+\mathrm{d} t_{J i}$

$r_{i}=\frac{u_{i}+c p_{i}}{e+\|\mathbf{u}\|+c\|\mathbf{p}\|}$

If $\|\mathbf{r}\| \geq \rho-e$, then update other $F_{1}$ units according to Eqs. (2), (4)-(6), and continue the following steps. Otherwise, return to Step 3 for finding the second largest signal and check again. If no pattern concords, this uncommitted node on the $F_{2}$ layer will be learnt and transformed as a new stored pattern.
Step 5. Update weights of the winning unit $J$ for a certain iterations until the weight changes are below some specified tolerance. Consequently, update $F_{1}$ activations according to Eqs. (1), (2), (4)-(6) and (9):

$t_{J i}=\alpha \mathrm{d} u_{i}+(1+\alpha d(d-1)) t_{J i}$

$b_{i J}=\alpha \mathrm{d} u_{i}+(1+\alpha d(d-1)) b_{i J}$

Step 6. Test the stopping condition for weight updates and for number of epochs involved. For example, repeat Steps 2 to 6 until the placement of output patterns does not change from one epoch to the next.

In this study, the results obtained from the ART2 network need to be further analyzed:

(i) Customer segmentation. The output patterns from the ART2 network are automatically formed based on the customer importance ratings of imposed constructs, i.e. the number of output pattern is identical to that of output cluster. In addition, the cumulative number of respondents in relation to each output pattern can be used as the criterion for subsequent marketing analysis.

(ii) Marketing analysis. Marketing analysis comprises major customer group identification, competition analysis and customer trends forecast. Firstly, the ART2 network outputs are organized according to multicultural customer groups such as age, gender and 
skill. Subsequently, major customer groups are identified from the output patterns that contain majority of respondents (or customers). Competition analysis is then conducted by comparing the output patterns with the number of respondents in those patterns from the surveying company and those from its main competitor. The customer trends forecast is then performed based on the output patterns as well as the number of respondents in those patterns.

\section{A case study on wood golf club design}

This case study involved the design of a wood golf club, and was based on the assumption that the respondents possess some knowledge about wood golf clubs. One hundred (100) respondents, inclusive of both external and internal customers, were chosen for the sake of $\mathrm{CAH}$ elicitation. Subsequently, the ART2 network was employed for customer clusters of output patterns. The respondents were divided into two categories of different gender, namely male and female golfers. Each category consisted of 50 respondents from golfers younger than 35 and 50 from golfers elder than 35. Furthermore, half of them belonged to beginner golfers and the others belonged to better amateur golfers. The respondents were asked to contribute their verbatim constructs upon probes by an interviewer during a total of six sessions of laddering.

Subsequently, after the $\mathrm{CAH}$ has been established, the customer importance ratings from ' 0.1 ' to ' 1.0 ' ( 0.1 stands for least important and 1.0 stands for most important) to imposed constructs were completed. In the same manner, three sets of customer data (100 respondents each) from customer ratings towards imposed construct were then used for the analysis of major customer groups, competition and customer trends analysis, residing in the aforementioned
CMA module. For examples, customer data from the surveying company versus its main competitor are used for competition analysis, and past and present customer data are used for customer trends analysis. Fig. 4 presents the graphical user interface (GUI) of the CAH formation, and Fig. 5 shows the graphical representation of laddering for the design of a wood golf club. A four-level laddering structure was obtained, together with six (6) imposed constructs, sixteen (16) superordinate constructs and fiftyone (51) verbatim constructs. It was observed that a large number of verbatim, superoradinate and imposed constructs elicited possessed overlapping (high commonality of distribution) facets. For example, the imposed constructs 'Design principle' and 'Manufacture/Assembly/Repair' are largely shared by basic demands for ease of part manufacture or change. On the other hand, conflicts (adverse correlation) between imposed constructs such as 'Cost/Price' versus 'Personal preference' can also be detected.

In this work, the ART2 network was employed after the respondents completed the importance ratings to each imposed construct. The graded imposed constructs were then organized into a feature matrix and used as inputs to the ART2 network for learning and customer group clustering. For instance, if six (6) imposed constructs are graded by one-hundred (100) respondents, an input matrix of $6 \times 100$ dimensions will form the input samples, as shown in Fig. 6. Fig. 7 shows the GUI of the inputs from customer information as well as customer ratings. The network's output is the pattern for customer group clusters, as explained in Section 3.2. Table 2 lists the initialized specifications of the ART2 network. Fig. 8 shows the training results of a sample input vector. Furthermore, the GUI of the network outputs is shown in Fig. 9.

Table 3 presents the ART2 network output results, which are organized according to multicultural customer groups

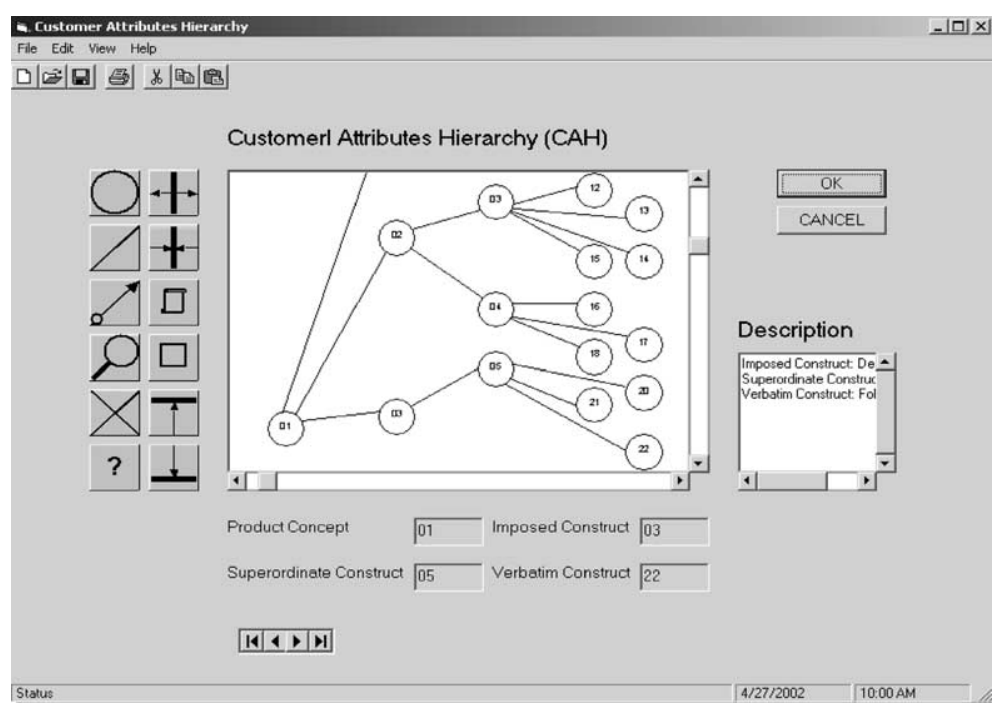

Fig. 4. GUI of CAH formation. 


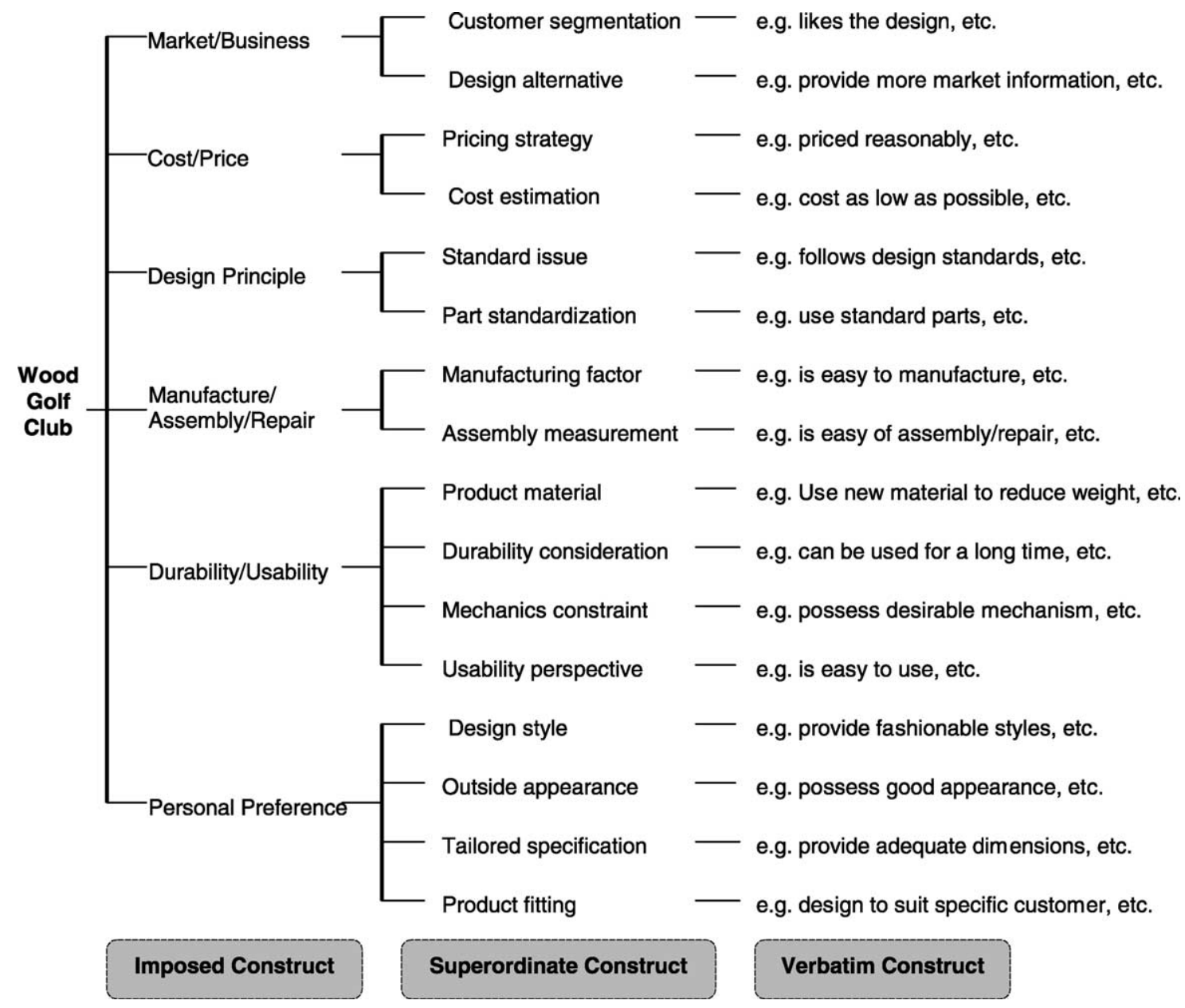

Fig. 5. CAH derived from the laddering process.

such as age, gender and skill. As shown in Table 3, five diversities (from Patterns 1 to 5) are identified, in which Patterns 2 and 3 are the major customer groups with 31 and 39 respondents out of one hundred respondents, respectively. From Fig. 10 and Table 3, it can be observed that:
- the network output of Pattern 2 is activated by female golfers rather than male golfers, as well as by the beginners rather than the better amateurs;

- the network output of Pattern 3 is mainly formed by the younger male golfers, where almost equivalent (a)

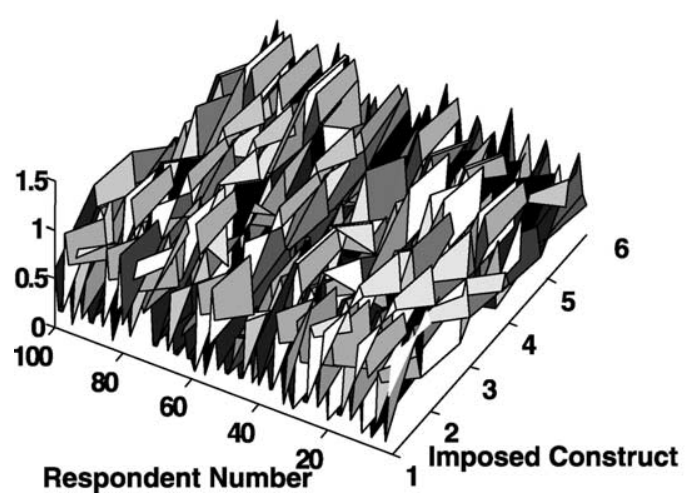

(b)

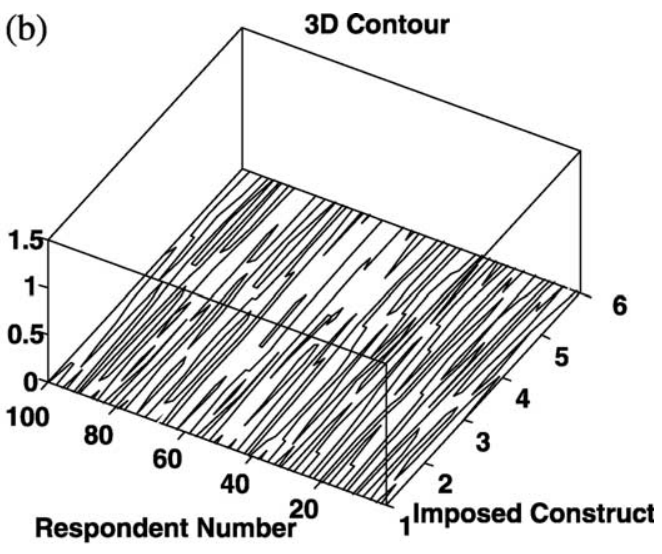

Fig. 6. Representation of input samples: (a) customer input space; (b) 3D contour of input space. 


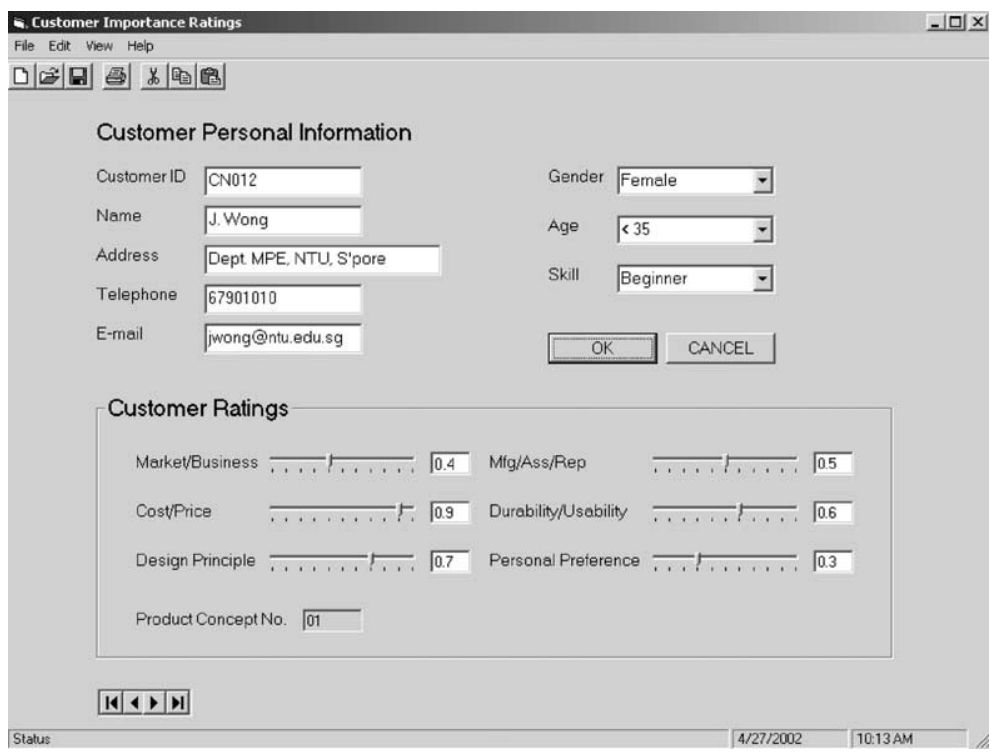

Fig. 7. GUI of customer information elicitation.

number of the beginners and better amateurs is detected;

- the network output of Pattern 1 possesses the medium statistical number of respondents, it implies that those male golfers elder than 35 are usually the better amateurs; and

- the network output of Patterns 4 and 5 can be regarded as minor customer groups with relatively small number of respondents

By the same token, Tables 4 and 5 list the results obtained from the ART2 neural network, which will be used for competition analysis and customer trends analysis, respectively. More specifically, the competition analysis can be conducted via comparing the results from surveying company (Table 3), and those from its main competitor (Table 4) and Fig. 11(a). Likewise, the customer trends analysis can also be proceeded on the basis of the results from the present customer data (Table 3), and those from the past customer data as shown in Table 5 and Fig. 11(b).

According to Tables 3 and 4, two major customer groups were observed from both the surveying company and its

Table 2

Initialized specifications of the ART2 neural network

\begin{tabular}{lc}
\hline Initial specification & Value \\
\hline Fixed weights $a$ & 10 \\
Fixed weights $b$ & 10 \\
Reset weights $c$ & 0.1 \\
Winning unit activation $d$ & 0.9 \\
Small-valued parameter $e$ & 0 \\
Noise suppression parameter $\theta$ & 0.4 \\
Learning rate $\alpha$ & 0.3 \\
Vigilance parameter $\rho$ & 0.7 \\
Initially, $u_{i}=0, p_{i}=0, q_{i}=0, t_{j i}=0, b_{i j} \neq 0$ & \\
\end{tabular}

main competitor, respectively. However, different customer orientations can still be identified between them as follows.

- a major customer group of the younger male beginner golfers was detected from both the surveying company and its main competitor (Pattern 3 in Table 3 and Pattern 4 in Table 4), respectively. Therefore, the customer orientation of this customer group could be treated as a competitive opportunity for both companies as no company was judged to be superior in this direction;

- a major customer group of the female beginner golfers (Pattern 2 in Table 3) was identified from the surveying company, which revealed that the surveying company possessed an advantage on this customer orientation against its main competitor; and

Training of Top-down Weights $t$

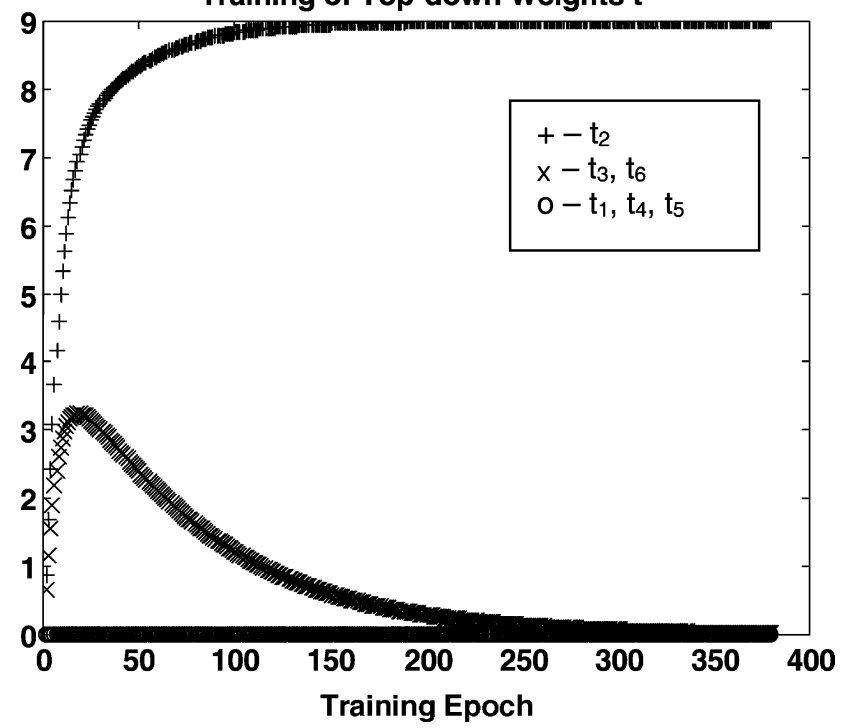

Fig. 8. An example of weights changes in the ART2 network training process. 


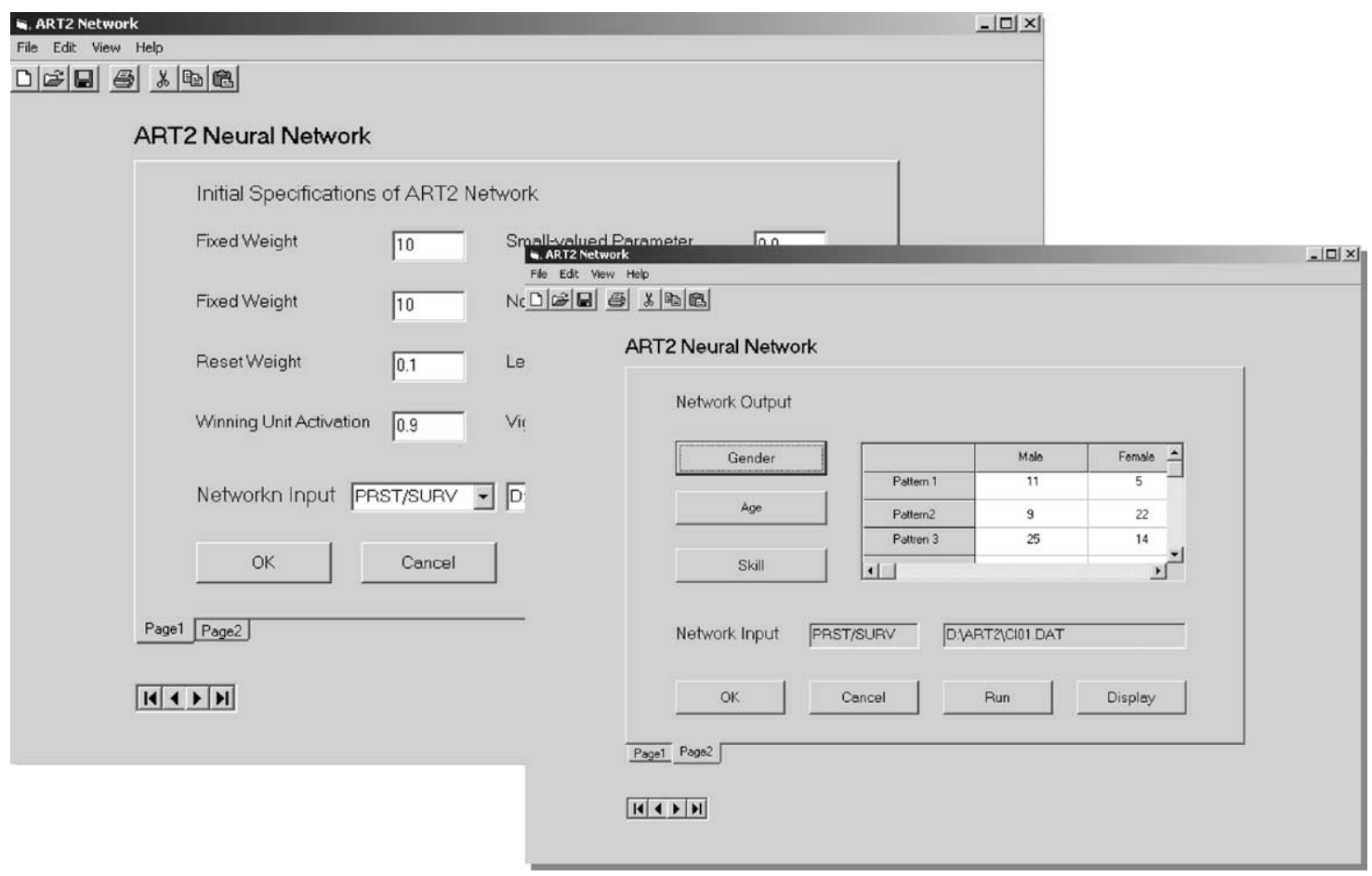

Fig. 9. GUI of network output generation.

Table 3

Results from the ART2 network regarding present data of the surveying company

\begin{tabular}{|c|c|c|c|c|c|c|c|}
\hline \multicolumn{2}{|c|}{ Multicultural customer group } & \multicolumn{5}{|c|}{ Output pattern } & \multirow[t]{2}{*}{ Sum } \\
\hline & & 1 & 2 & 3 & 4 & 5 & \\
\hline \multirow[t]{2}{*}{ Age } & $<35$ & 2 & 16 & 29 & 0 & 3 & 50 \\
\hline & $\geq 35$ & 14 & 15 & 10 & 5 & 6 & 50 \\
\hline \multirow[t]{2}{*}{ Gender } & Male & 11 & 9 & 25 & 4 & 1 & 50 \\
\hline & Female & 5 & 22 & 14 & 1 & 8 & 50 \\
\hline \multirow[t]{2}{*}{ Skill } & Beginner & 5 & 22 & 21 & 0 & 2 & 50 \\
\hline & Better amateur & 11 & 9 & 18 & 5 & 7 & 50 \\
\hline Sum per group & & 16 & 31 & 39 & 5 & 9 & 100 \\
\hline
\end{tabular}

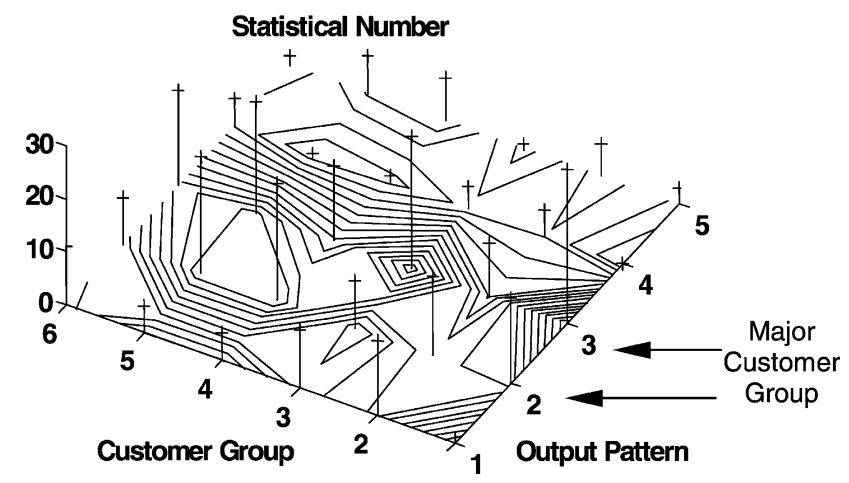

Fig. 10. Representation of statistical respondent number from the ART2 network (Present customer data of the surveying company).
Table 4

Results from the ART2 network regarding present data of main competitor

\begin{tabular}{|c|c|c|c|c|c|c|}
\hline \multicolumn{2}{|c|}{ Multicultural customer group } & \multicolumn{4}{|c|}{ Output pattern } & \multirow[t]{2}{*}{ Sum } \\
\hline & & 1 & 2 & 3 & 4 & \\
\hline \multirow[t]{2}{*}{ Age } & $<35$ & 10 & 9 & 3 & 28 & 50 \\
\hline & $\geq 35$ & 9 & 23 & 8 & 10 & 50 \\
\hline \multirow[t]{2}{*}{ Gender } & Male & 3 & 19 & 7 & 21 & 50 \\
\hline & Female & 16 & 13 & 4 & 17 & 50 \\
\hline \multirow[t]{2}{*}{ Skill } & Beginner & 16 & 12 & 3 & 19 & 50 \\
\hline & Better amateur & 3 & 20 & 8 & 19 & 50 \\
\hline Sum per group & & 19 & 32 & 11 & 38 & 100 \\
\hline
\end{tabular}

Table 5

Results from the ART2 network regarding past data of the surveying company

\begin{tabular}{|c|c|c|c|c|c|}
\hline \multicolumn{2}{|c|}{ Multicultural customer group } & \multicolumn{3}{|c|}{ Output pattern } & \multirow[t]{2}{*}{ Sum } \\
\hline & & 1 & 2 & 3 & \\
\hline \multirow[t]{2}{*}{ Age } & $<35$ & 24 & 5 & 21 & 50 \\
\hline & $\geq 35$ & 41 & 7 & 2 & 50 \\
\hline \multirow[t]{2}{*}{ Gender } & Male & 39 & 1 & 10 & 50 \\
\hline & Female & 26 & 11 & 13 & 50 \\
\hline \multirow[t]{2}{*}{ Skill } & Beginner & 27 & 4 & 19 & 50 \\
\hline & Better amateur & 38 & 8 & 4 & 50 \\
\hline \multicolumn{2}{|c|}{ Sum per group } & 65 & 12 & 23 & 100 \\
\hline
\end{tabular}



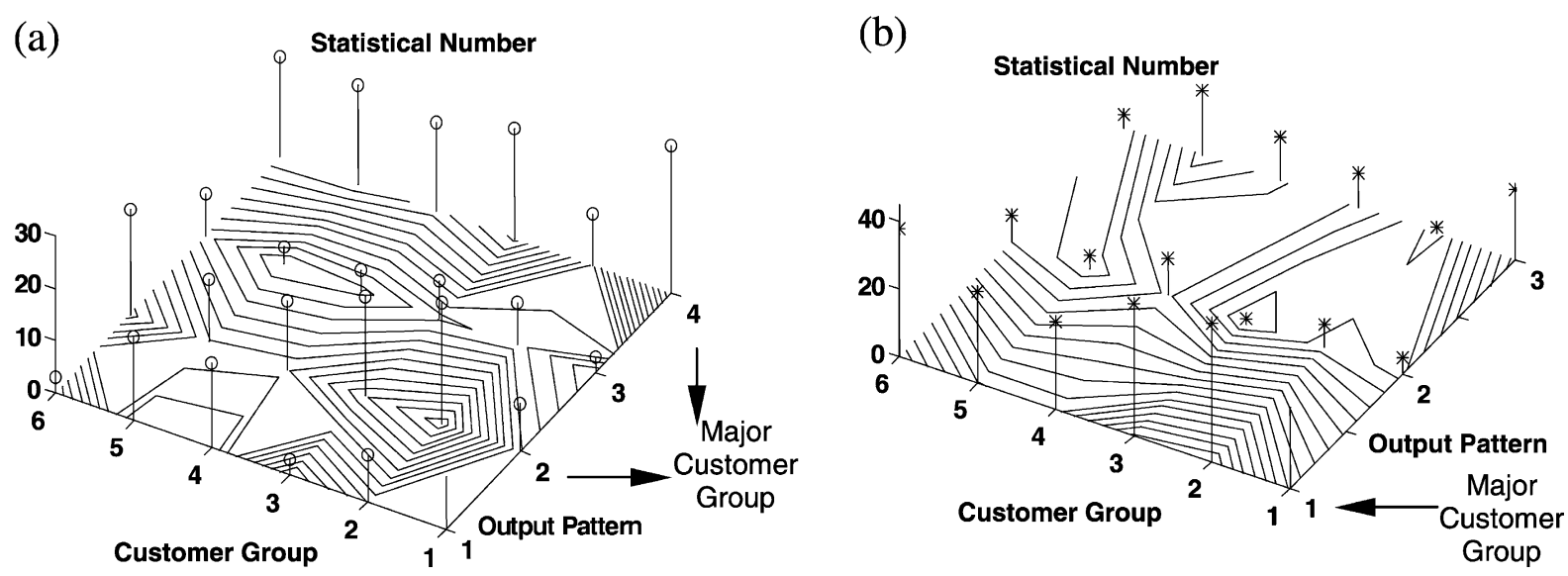

Fig. 11. Representation of statistical respondent number from the ART2 network: (a) present customer data of main competitor; (b) past customer data of the surveyed company.

- a major customer group of the high-skilled elder male golfers (Pattern 2 in Table 4) was found from the main competitor. It implied that the surveying company is behind its main competitor upon this customer orientation.

Refer to Tables 3 and 5, it can be summarized that

- Fewer customer orientations as well as major customer groups were existed previously, which means fewer product concepts or design alternatives were demanded by customers in the past than at present; and

- In the context of the major customer groups, the customer orientation has shifted from the high-skilled male golfers elder than 35 (Pattern 1 in Table 5 and Fig. 11(b)) in the past to the female or younger golfers at present (Patterns 2 and 3 in Table 3 and Fig. 10)

\section{Conclusions}

It is highly desirable to establish a systematic approach for customer and marketing analysis as the initial or fundamental investigation prior to product concept formation. Based on this conception, a prototype system that concerns with the breadth and depth of customer requirements solicitation has been proposed and demonstrated in this study. The prototype system, which emphasizes the customers' perception of a specific product and the conflict of customer requirements derived from multicultural customer groups, comprises two interrelated components, namely, CRE module and CMA module. As different customer orientations may bring about different design variants (or alternatives), the prototype system can be treated as a front-end decision making module such as design specification generation and product platform formation of a comprehensive system for product conceptualization [30]. Basically, the prototype system synthesizes the customer involvement and marketing analysis, starting from the voice of customers and ending with the identified opportunities from marketing analysis. As a result, the proposed prototype system possesses the following strengths.

- The laddering technique can systematically elicit the customer requirements and then organize them using the so-called CAH for further analysis.

- The ART2 neural network can effectively evaluate the multicultural factors during customer and marketing analysis

A case study on wood golf club design was used to illustrate the performance of the proposed approach. In the case study, the laddering technique has demonstrated its effectiveness in eliciting customer requirements in the early stage of NPD. The ART2 neural network that requires simple input matrices of graded imposed constructs provides an efficient means to analyze competition and customer trends statistically. It is envisaged that with the genuine voice of customers as well as the competition and customer trends identified, more reasonable product definitions or concepts can be gleaned. As a result, organizations can gain a competitive edge in NPD.

\section{References}

[1] DuBrin AJ. Essentials of management. Cincinnati: South-Western Publishing; 1994.

[2] Christopher MC, McDonald M, Wills G. Introducing marketing. London: Pan; 1980.

[3] Berry LL. Services marketing is different. Business Horizons 1980; May-June:24-9.

[4] Gorton K, Doole I. Low-cost marketing research: a guide for small business. New York: Wiley; 1983.

[5] Shapiro BP, Bonoma TV. How to segment industrial markets. Harvard Business Rev 1984;62(3):104-10. 
[6] Lancaster G, Lomas RA. Forecasting for sales and materials management. London: Macmillan Press; 1985.

[7] Hörte SÁ, Ylinenpää H. The firm's and its customers' views on orderwinning criteria. Int J Oper Prod Mgmt 1997;17(10):1006-19.

[8] Lilien GI, Rangaswamy A. Marketing engineering: computer-assisted marketing analysis and planning. New York: Addison-Wesley; 1997.

[9] Jones SL. All-to-one: the winning model for marketing in the postinternet economy. London: McGraw-Hill; 2001.

[10] Mohr J. Marketing of high-technology products and innovations. Prentice-Hall: Upper Saddle River; 2001.

[11] Bitner MJ. Contextual cues and customer satisfaction: the role of physical surrounding and employee behavior in services settings. University of Washington, PhD Thesis; 1987.

[12] Curry J. Know your customers: how customer marketing can increase profits. London: Kogan-Page; 1991.

[13] Geddes L. Through the customers' eyes: improving your company's results with the CORe $^{\mathrm{TM}}$ method. New York: Amacom; 1993.

[14] Goldzimek LS, Beckmann GL. Customer driven: a revolutionary system for putting golden handcuffs on your customers. London: Hutchinson Business Books; 1989.

[15] Chrisholm J. Using the Internet to measure customer satisfaction and loyalty. In: Zemke R, Woods JA, editors. Best practices in customer service. New York: Amacon; 1999.

[16] Barness JG. Closeness, strengths and satisfaction: examining the nature of relationships between providers and financial services and their retail customers. Psychol Market 1997;14(8):765-90.

[17] Crönroos C. From marketing mix to relationship marketing: towards a paradigm shift in marketing. Mgmt Decision 1994;32(2):4-20.

[18] Shetch JN, Sharma A. Supplier relationships: emerging issues and challenges. Ind Market Mgmt 1997;26(2):91-100.

[19] Andaleeb SS. An experimental investigation of satisfaction and commitment in marketing channels: the role of trust and dependence. J Retail 1996;72(1):77-93.

[20] Wilson DT. An integrated model of buyer-seller relationship. J Acad Market Sci 1995;23(4):335-45.

[21] Ganesan S. Determinants of long-term orientation in buyer-seller relationship. J Market 1994;58(2):1-19.

[22] Robicheaux RA, Coleman JE. The structure of marketing channel relationships. J Acad Market Sci 1994;22(1):38-51.

[23] Kumar N, Scheer LK, Steenkamp Jr. BEM. The effects of perceived interdependence on dealer attitudes. J Market Res 1995;32(3): $348-56$.

[24] Shetch JN, Parvatiyar A. Relationship marketing in consumer markets: antecedents and consequences. J Acad Market Sci 1995; 23(4):255-71.

[25] Lancaster G, Massingham L. Marketing management. New York: McGraw-Hill; 1993.

[26] Kotler P. Marketing management: analysis, planning implementation and control. Engelwood Cliffs: Prentice-Hall; 1991.

[27] Tugendhat C. The multinationals. Hamondsworth: Penguin; 1984.

[28] Darwin CR. On the origin of the species. Oxford: Oxford University; 1859.

[29] Lancaster G, Massingham L. The essentials of marketing: text and cases. Hong Kong: McGraw-Hill; 1994.

[30] Khoo LP, Chen $\mathrm{CH}$, Yan W. An investigation on a prototype customer-oriented information system for product concept development. Comput Ind 2002;49(2):157-74.

[31] Nielson CC. An empirical examination of the role of 'closeness' in individual buyer-seller relationships. Eur J Market 1998;32(5/6): 441-63.

[32] Bennett R. Relationship formation and governance in consumer markets: transactional versus behaviorist approach. J Market Mgmt 1996; 12:417-36.
[33] Louder D, Bitta AJD. Consumer behavior: concepts and applications. London: McGraw-Hill; 1988.

[34] Rugg G, McGeorge P. Laddering. Expert Syst 1995;12(4):279-91.

[35] Kelly GA. The psychology of personal constructs. New York: W. W. Norton; 1955.

[36] Hinkle D. The change of personal constructs from the viewpoint of a theory of construct implications. Ohio State University: Unpublished PhD Thesis; 1965.

[37] Shadbolt NR, Burton AM. Knowledge elicitation. In: Wilson J, Corlett N, editors. Evaluation of human work: practical ergonomics methodology. New York: Taylor and Francis; 1989.

[38] Boose JH, Bradshaw JM. Expertise transfer and complex problems: using AQUINAS as a knowledge-acquisition workbench for knowledge based systems. In: Boose J, Gaines BR, editors. Knowledgebased systems-volume, vol. 2. New York: Academic Press; 1988.

[39] Fransella F, Bannister D. A manual for repertory grid technique. London: Academic House; 1977.

[40] McGeorge P, Rugg G. The use of contrived knowledge elicitation techniques. Expert Syst 1992;9(3):149-54.

[41] Shaw MLG, Gaines BR. Requirements acquisition. Software Engng J 1996;11:149-65.

[42] Maiden NAM, Rugg G. ACRE: selection methods for requirements acquisition. Software Engng J 1996;11:183-92.

[43] Chen CH, Khoo LP, Yan W. Multicultural factors evaluation on elicited customer requirements for product concept development. Proceedings of 16th International Conference for Production Research (ICPR-16), Prague, Czech; July 29-August 3 2001. p. 15.

[44] Yan W, Chen CH, Khoo LP. A radial basis function neural network multicultural factors evaluation engine for product concept development. Expert Syst 2001;18(5):219-32.

[45] Yan W, Chen CH, Khoo LP. An integrated approach to the elicitation of customer requirements for engineering design using picture sorts and fuzzy evaluation. Artif Intell Engng Design, Anal Manufact 2002; 16(2):59-71.

[46] Schiffman LG, Kanuk LL. Consumer behavior. Engelwood Cliffs: Prentice-Hall; 1987.

[47] Engel JF, Blackwell RD, Miniard PW. Consumer behavior. Hinscale: Dryden Press; 1986.

[48] Stanton WJ, Sommers MS, Kanuk JG. Fundamentals of marketing. New York: McGraw-Hill; 1977.

[49] John J, Hauser R, Clausing D. The house of quality. Harvard Business Rev 1988;66(3):63-73.

[50] Clifton P, Nguyer H, Nutt S. Marketing analysis and forecasting. London: Heinemann; 1985.

[51] Mazanec JA. Positioning analysis with self-organising maps: an exploratory study on luxury hotels. Cornell Hotel Restaurant Admin Quart 1995;36:85-90

[52] Brooks C. Linear and non-linear (non-) forecastability of highfrequency exchange rates. J Forecast 1997;16:125-45.

[53] Cotrell M, Girard B, Rousset P. Forecasting of curves using a Kohonen classification. J Forecast 1998;17:429-39.

[54] Curry B, Davies F, Philips P, Evans M, Moutinho L. The Kohonen self-organizing map: an application to the study of strategic groups in the UK hotel industry. Expert Syst 2001;18(1):19-30.

[55] Nilson TH. Chaos marketing-how to win in a turbulent world. Shappenhangers: McGraw-Hill; 1995.

[56] Haykin S. Neural networks: a comprehensive foundation. Engelwood Cliffs: Prentice-Hall; 1999.

[57] Principe JC, Euliano NR, Lefebevre WC. Neural and adaptive systems: fundamental through simulations. New York: Wiley; 2000.

[58] Carpenter G, Grossberg S. ART2: stable self-organization of pattern recognition codes for analog input patterns. Appl Optics 1987;26: 4919-30. 